\title{
Problems of caregiving spouses of patients with dementia
}

Citation for published version (APA):

Commissaris, C. J. A. M., Jolles, J., Verhey, F. R. J., \& Kok, G. J. (1995). Problems of caregiving spouses of patients with dementia. Patient Education and Counseling, 25(2), 143-149.

https://doi.org/10.1016/0738-3991(95)00718-F

Document status and date:

Published: 01/01/1995

DOI:

10.1016/0738-3991(95)00718-F

Document Version:

Publisher's PDF, also known as Version of record

\section{Please check the document version of this publication:}

- A submitted manuscript is the version of the article upon submission and before peer-review. There can be important differences between the submitted version and the official published version of record.

People interested in the research are advised to contact the author for the final version of the publication, or visit the DOI to the publisher's website.

- The final author version and the galley proof are versions of the publication after peer review.

- The final published version features the final layout of the paper including the volume, issue and page numbers.

Link to publication

\footnotetext{
General rights rights.

- You may freely distribute the URL identifying the publication in the public portal. please follow below link for the End User Agreement:

www.umlib.nl/taverne-license

Take down policy

If you believe that this document breaches copyright please contact us at:

repository@maastrichtuniversity.nl

providing details and we will investigate your claim.
}

Copyright and moral rights for the publications made accessible in the public portal are retained by the authors and/or other copyright owners and it is a condition of accessing publications that users recognise and abide by the legal requirements associated with these

- Users may download and print one copy of any publication from the public portal for the purpose of private study or research.

- You may not further distribute the material or use it for any profit-making activity or commercial gain

If the publication is distributed under the terms of Article $25 \mathrm{fa}$ of the Dutch Copyright Act, indicated by the "Taverne" license above, 


\title{
Problems of caregiving spouses of patients with dementia
}

\author{
C.J.A.M. Commissaris ${ }^{a}{ }^{a}$, J. Jolles ${ }^{\text {a }}$, F.R.J. Verhey Jr. ${ }^{\text {a }}$, G.J. Kok ${ }^{\text {b }}$ \\ ${ }^{a}$ Department of Neuropsychology, Neuropsychiatry and Psychobiology, University of Limburg, P.O. Box 616, 6200 MD Maastricht, \\ The Netherlands \\ ${ }^{\mathrm{b}}$ Department of Health Education, University of Limburg, Maastricht, The Netherlands
}

Received 31 May 1994; accepted 29 January 1995

\begin{abstract}
Twenty-six caregiving spouses of patients with dementia in the Netherlands were interviewed to better understand their problems and needs. Special attention was paid to the information the caregivers received from their general practitioner. Nineteen caregivers indicated that they received little or no information about the disease and its possible consequences. Furthermore, they experienced many problems, because of the disease and the daily care they provided; eleven caregivers indicated a decrease in social contact, which resulted in further problems. Caregivers who sought professional help at an early stage experienced fewer problems in providing daily care. The results of this project suggest that in future health education policy special attention should be paid to the role of the general practitioner and to the importance of a caregiver's social network.
\end{abstract}

Keywords: Dementia; Health education; Social contacts; Information; General practitioner

\section{Introduction}

The Netherlands has approximately 15 million inhabitants. At the moment, it is estimated that there are about 300000 people who suffer from mild or severe dementia [1]. As a result of the aging of the population, it is expected that in the next decades society and healthcare workers will be confronted with an increasing number of elderly people with dementia. The shortage of beds in nursing homes and other facilities, which is

\footnotetext{
"This paper was presented at the 2nd National Alzheimer Congress in Adelaide, Australia, 2-4 March 1992.

* Corresponding author.
}

already a problem, will increase considerably in the near future. This implies that most of the care for these people will have to be provided by the spouse, children, grandchildren, friends, neighbors, or volunteers.

A lot of research, especially in the last decade, has been carried out to gain a clearer view of the problems and the needs of people who are the primary caregivers for their demented spouses [2-9]. Most of these research projects arrive at the same general conclusions. People taking care of their demented spouses have all kinds of problems because of the nature of the disease and the daily care they have to provide. These problems can be 
physical, psychological, social, or financial. The fact that these problems occur is not surprising. Dementia is a disease with very severe and drastic consequences for all those who are involved. The emotional reactions of caregivers to the changes in their lives as a result of their partner's disease can be described as mourning behavior. In the literature, this is often called 'anticipated mourning' [10].

As a result of the disease contact with family and friends may become less frequent, causing increasing social isolation. Social contact is of great importance in relation to health [11]. Important reasons for losing social contact with relatives and friends are not only feelings of shame on the part of the caregiver, but also existing taboos and prejudices about dementia in our society. The cause of misunderstanding is often a lack of knowledge about the disease and difficulties in coping with a demented person, how to behave, and how to deal with the social environment.

According to the study by George and Gwyther [4], the well-being of the caregiver is not correlated with the duration of the disease and is only slightly correlated with the severity of the disease. The well-being of caregivers is mainly determined by the resources and support that are available to them.

Apart from providing caregivers with support, it is also important that caregivers have sufficient knowledge about the disease, its course, and possible consequences for both the patient and his or her social environment. Chenoweth and Spencer [2] found that families who have more knowledge about the disease and its possible consequences are better able to cope with the problems as they occur and with the patient's unusual behavior in daily life. However, the majority of the families involved in the study had received little or no information from their general practitioner. Another study also showed that spouses and other family members of persons diagnosed as 'having a dementia syndrome' received very little information from their doctor about the diagnosis and the problems that might occur [12].

Previous research in the Netherlands revealed an enormous increase in the number of articles about dementia in daily and weekly news magazines [13]. However, the number of articles that could have a high impact from an educational point of view has not increased. Therefore, carefully planned public education about the differences between forgetfulness and dementia is important and has already proved to be successful [14-15].

The present study was conducted to gain a better understanding of the problems of caregiving spouses of patients with dementia in the Netherlands. This insight is necessary because one of the best predictors for institutionalization is that caregivers can no longer provide the care at home that the patient needs [16-18]. A better understanding is also of great importance for the planning of future healthcare policy and education in this area in order to contribute to the prevention of physical and psycho-sociological problems of spouses of dementia patients. The emphasis in this explorative study was on education provided to the caregiving spouses. Problems experienced by the caregivers were made operational in terms of difficulties with daily care, the problems that occur as a consequence of the daily care, the need for help with the daily care, the need to talk to other caregivers of patients with dementia, and the extent to which the caregiver has complaints of a depressive nature [19]. Several independent variables were investigated to find out to what extent they contribute to the problems experienced by the caregivers. Besides our main objective to gain more insight into the problems perceived by caregivers of dementia patients, three research questions were investigated. (1) Do caregivers who received information from the general practitioner about the disease and the possible consequences of the disease, experience less problems with the daily care of their spouse? (2) How important are social contacts for the caregiver and for his or her subjective experience of problems? (3) How important is seeking professional help at as early a stage as possible for caregivers' experience of problems at a later stage of the disease?

\section{Methods}

\subsection{Sampling}

Our target group were home caregiving spouses of patients with dementia aged 50 years and older. 
Other inclusion criteria were: that the spouse was acquainted with the diagnosis of 'dementia syndrome', made using standard criteria [20-21] and the spouse was intellectually capable of giving a reliable opinion about the situation. Patients suffering from another disease that might have an impact on the care they need were excluded from this study. Seventeen patients came from the Maastricht Memory Clinic [22] and nine from the Regional Mental Health Institute. Thus the group was not representative of the whole group of patients with dementia and their caregivers, because the caregivers had already sought professional help. Most patients were suffering from Alzheimer's disease and a few were diagnosed as 'multi-infarct-dementia' (MID).

\subsection{The interview}

All interviews took place at home, in the absence of the demented spouse. Each interview lasted on average an hour and a half; a structured questionnaire was used. The questions were divided into several categories: demographic characteristics of the caregiver and the patient; the duration of the disease; seeking of professional help; the information and explanation caregivers received from their general practitioner; difficulty in providing daily care (assessed with a five-point Likert scale, varying from very difficult to not difficult at all); the help the caregiver already receives and would like to receive; the help the patient needs with daily activities, such as washing and eating; the main problems for the caregiver as a result of the disease (Table 1); contact with family and friends since the patient was diagnosed; physical and mental problems of the caregiver, and the need to talk to other spouses of patients with dementia.

The ZUNG self-rating questionnaire [19] was used to give an indication of complaints of a depressive nature. The ZUNG consists of 20 items and scoring is with a five-point Likert scale. The minimum score is 20 and the maximum is 100 . In this study, the extent to which daily help was required by the patient was considered as an indicator of the severity of the disease. There was no other criterion used for disease severity at the time of the interview.

\subsection{Demographic characteristics}

The group of patients consisted of 17 men and 9 women, with ages ranging from 55 to 90 years and an average of 70 years. The patients were diagnosed as suffering from dementia 2 years earlier (the range was from 6 months to 8 years). Eighteen caregivers were able to remember how long they had waited to seek professional help after they had noticed the first symptoms and signs in their spouse. On average, they waited more than 2 years (range, a few months to 5 years). The group of caregivers consisted of 18 females and eight males. In one case the caregiver was not the spouse but an unmarried sister who lived with the patient. The average age of the caregivers was 68 years, with a range of 50-88 years.

The average score of the 26 caregivers on the ZUNG depression scale was 39 , varying from 25 until 63. The scores showed a normal deviation.

\section{Results}

\subsection{Problems perceived by caregivers}

The caregivers were first asked to indicate how they coped with the daily care of their demented spouse. Nine caregivers found daily care extremely difficult or very difficult. Seven caregivers said 'I'm doing all right', and nine caregivers found that daily care was not difficult. Nine people wished to talk to other spouses of patients with dementia in order to exchange experiences. The others did not wish to for different reasons, mainly because they did not want to hear about the problems of other people. Table 1 shows the most important problems the caregivers mentioned as a result of the disease.

The problems in Table 1 are ranked according to the extent to which caregivers had problems with the daily care he or she provides. Cronbach's alpha of this problem scale is 0.60 , indicating a moderate internal consistency. The main problems mentioned were a lack of time for themselves and the fact that it was not possible to have a conversation with the patient. Nine caregivers reported physical problems, which were mainly cited as cardiac in nature, or as tension headaches. From a $t$-test it appeared that caregivers with physical 
Table 1

Main problems of caregiving spouses of patients with dementia $(N=26)^{*}$

\begin{tabular}{lr}
\hline Lack of time for themselves & 12 \\
Conversation not possible with patient & 11 \\
Physical problems of the caregiver & 9 \\
Lack of help in daily care & 9 \\
Daily contact with spouse & 8 \\
Aggressive behavior of the patient & 8 \\
Disorientation of the patient & 5 \\
Incontinence of the patient & 4
\end{tabular}

*Each caregiver could give more than one answer.

problems were also more likely to score higher on the ZUNG depression scale $(t=2.5 ; P<0.05)$.

Nine caregivers did not have any help in the daily care of their spouses. The people who did get help were mainly supported by their children, district nurses, neighbors, grandchildren, and other family members. Four people had a great need for help, nine people wished for a bit more help, and 13 caregivers did not need help. People receiving the most help had the lowest need for (more) additional help. Furthermore, it appeared that the more problems caregivers had as a consequence of the daily care, the more complaints of a depressive nature they reported $(r=0.61 ; P<$ $0.01)$ and the more they would like help from others $(r=0.47 ; P<0.01)$. Caregivers with a need to talk to other caregivers were more depressed $(t=2.2 ; P<0.05)$ and also had a greater need of help with the daily care of the patient.

The caregivers were then asked how much help the patients needed with daily activities. Nine patients needed a lot of help, four patients needed some help, and 13 patients did not need any help or hardly any help. Most help was required when patients went to the toilet, washed and dressed themselves, looked for things they had lost, and ate. In this study the help required was considered as an indicator of disease severity. Pearson correlations showed a positive correlation between the severity of the disease and the difficulty the caregiving spouse experienced in providing the daily care $(r=0.39 ; P<0.05)$. The duration of the disease (according to the caregiver) was not correlated with any variable that measures the extent to which the caregiver experienced problems with the daily care of the demented spouse. This finding corresponds with the results of George and Gwyther [4].

\subsection{Answering the research questions}

\subsubsection{Information about the disease}

As in the study by Chenoweth and Spencer [2], we examined the content of the information which the caregivers received from their general practitioner after the patient was diagnosed as suffering from dementia. We looked at the information the caregivers reported having received about the disease, the possible consequences of the disease for both patient and caregiver, information about coping with problems that might occur in daily care, and information about organizations which provide help and support. The answers of 23 caregivers were used and are presented in Table 2. Three caregivers did not consult their physician.

From our research it appears that caregivers received little information from their general practitioner. The following are a few examples of what they were told: 'The brain cells are diminishing. This can be a quick or a slow process; enjoy the time that is left' or 'Don't forget to take care of yourself as well' and 'Experience will teach you how to cope with it'. These examples can not be classified as 'information'. Ten caregivers said they did not receive any information from their physician. The five items in Table 2 represent the information received after the diagnosis was made (Cronbach's alpha is 0.59). From further analysis it appeared that people who received little or no

Table 2

The information caregivers reported receiving from their general practitioner $(N=23)^{*}$

\begin{tabular}{ll}
\hline The disease and its course & 3 \\
Possible problems for the patients & 4 \\
Possible problems for the caregiver & 4 \\
Coping with problems in daily life & 2 \\
Organizations which provide help and & 7 \\
$\quad$ support &
\end{tabular}

*Each caregiver could give more than one answer. 
information found coping with daily care much more difficult $(r=0.38 ; P<0.05)$, independent of the severity and duration of the disease and the age of the caregiver. Although a correlation between information and the problems mentioned in Table 1 was also expected, no significant correlation was found.

\subsubsection{Social contacts}

As mentioned in the introduction, one of the problems that may occur as a consequence of the disease, is that the caregiver loses contact with relatives and friends. In our study, 10 caregivers indicated that contact with their family had diminished since the disease had become established in the patient. Only one caregiver reported that contact had increased. In all other caregivers there was no change. Eleven caregivers reported a decrease in social contact with friends and acquaintances. The other caregivers reported no change. The decrease in social contact was highly correlated with an increased incidence of depressive complaints in the caregiver $(r=0.49$; $P<0.05$ ). People with fewer social contacts reported more problems as a result of the disease $(r=0.59 ; P<0.01)$, and the more social contacts had decreased, the more help the caregivers desired $(r=0.42 ; P<0.05)$. One of the characteristics of people who expressed a need to talk with other caregiving spouses was a severe decrease in their social contacts $(t=3.9 ; P<$ $0.01)$. The more severe the disease, the more the contact with relatives and friends had decreased $(r=0.40 ; P<0.05)$.

\subsubsection{Seeking professional help}

From this study it appeared that people who waited longer until seeking professional help after they noticed the first symptoms in their spouse, experienced more problems (Table 1) with the daily care they provided than people who went to the general practitioner earlier $(r=0.51 ; P<$ 0.05 ). These findings confirm the importance of early detection and diagnosis of dementia [23].

\section{Discussion}

The main goal of this explorative study was to gain more insight into the problems and needs of 26 caregiving spouses of patients with dementia. Based on previous literature, three research questions were investigated. One of the most important determinants of perceived problems from a health educational point of view was the information and explanation that the caregivers (say they) received from their general practitioner after the diagnosis was made. Therefore, the first research question was to find out whether caregivers who received information from the general practitioner about the disease and the possible consequences of the disease, experienced less problems with the daily care of their spouse.

The information and explanation given by the general practitioner about the disease appeared to be very poor, although the need for this information was apparently present. Chenoweth and Spencer reported comparable results [2]. It should be noted that the information received was assessed subjectively by the caregivers themselves. No information was available about the information they had actually received. Information about the disease was shown to be very important, because people who received little or no information found coping with daily care more difficult, independent of the severity and duration of the disease and the age of the caregiver. Several explanations can be given for the reported lack of information. First, it is possible that the caregiver really meant that he or she had wanted more emotional support. General practitioners often have too little time for this aspect and have insufficient knowledge of or ability to talk about such difficult subjects. Second, it is possible that, because of the emotions raised by the diagnosis and the disease, the caregiver was distracted from hearing what their general practitioner told them. Further research is necessary to gain a better understanding of this topic.

The second research question was to gain more insight into the importance of social contact for the caregiver and for his or her subjective experience of problems. Eleven caregivers reported a decrease in contact with family and friends since the disease of the patient had become established. This was especially so when the disease became more severe. This caused further isolation of the caregiver, just when much practical and emotional 
support was needed. The decrease in social contact was highly correlated with an increased incidence of complaints of a depressive nature for the caregiver and more perceived problems in daily life. Longitudinal or experimental research is necessary to draw conclusions about the causality of these correlations.

The third research question was to find out the importance of seeking help at as early a stage as possible. This was made operational by the time people (say they) had waited until seeking professional help after they had noticed the first symptoms of change in their spouse. The results show that the longer people waited, the more problems they experienced at a later stage with the daily care. These findings confirm the importance of early detection and diagnosis of dementia.

In conclusion, giving spouses of patients with dementia more information about the disease and its course is one of the ways that their problems and needs can be met as much as possible. With correct and adequate information, caregivers are better prepared for the problems that might occur. Special attention should be paid to teaching the caregiver how to cope adequately with the demented spouse and the problems that occur in daily life. Emphasis should also be given to the importance of social contact and how to retain or build up a social network. General practitioners can play an important role in providing initial information once the diagnosis is made. It is of great importance that this information is given at a suitable moment and not when there is, for example, considerable emotional distress. Information about organizations which provide practical and emotional support and help should be part of the standard information provided. Therefore, the general practitioner needs sufficient knowledge and skills. Experts in the field of health education can contribute to providing general practitioners with the necessary knowledge and skills; in this way general practitioners can play an intermediary role. He or she is the main person to provide initial information to the families of a demented patient. At a later stage, caregivers may wish to contact other healthcare workers, such as district nurses. These professionals should also have sufficient knowledge and skills to deal with both patients' and caregivers' problems and also to cope with difficult situations that might occur. Cooperation between different groups of healthcare workers confronted with patients with dementia in their daily work is essential for such a system to be successful $[24,25]$.

Finally, there are some recommendations about the information that should be given to the general public. Because of the importance of an early diagnosis, it is necessary that the general public has sufficient information about dementia, its causes, and the first symptoms. Because a dementia syndrome is not always incurable, people should know when to seek professional help. However, it is also important to know when it is not dementia, but something else. Many people, especially the elderly, worry about their diminishing memory and about the possibility that they may become demented $[14,15,26]$. When too much attention is paid to dementia in mass media campaigns, those people who are already insecure about their memory may become even more frightened or worried. More than $90 \%$ of all people aged 65 years and older will not become demented [1]. Therefore, attention should also be paid to information about normal forgetfulness as a part of the normal aging process $[13,14]$. This should prevent unnecessary anxiety about dementia in the elderly.

\section{References}

[1] Duin CM van. Risk factors for Alzheimer's disease. Genetic epidemiologic study. Rotterdam: Thesis, 1992.

[2] Chenoweth B. Spencer B. Dementia: the experience of family caregivers. Gerontologist 1986; 26: 267-272.

[3] Fitting M, Rabins P, Lucas MJ, Eastham J. Caregivers for dementia-patients: a comparison of husbands and wives. Gerontologist 1986; 26: 248-252.

[4] George LK, Gwyther LP. Caregiver well-being: a multidimensional examination of family caregivers of demented adults. Gerontologist 1986; 26: 253-259.

[5] Gilhooly ML. Senile dementia: factors associated with caregivers' preference for institutional care. $\mathrm{Br} \mathrm{J}$ Med Psychol 1986; 59: 165-171.

[6] Motenko AK. The frustrations, gratifications and wellbeing of dementia caregivers. Gerontologist 1989; 29: 166-172.

[7] Pruchno RA, Resch NL. Husbands and wives as caregivers: antecedents of depression and burden. Gerontologist 1989; 29: 159-165.

[8] Scott JP, Roberto KA, Hutton T. Families of 
Alzheimer's victims. Family support to caregivers. JAGS 1986; 34: 348-354.

[9] Zarit SH, Todd PA, Zarit JM. Subjective burden of husbands and wives as caregivers; a longitudinal study. Gerontology 1986; 26: 260-266.

[10] Teursink JP, Mahler S. Helping families cope with Alzheimer's disease. Hosp Commun Psychiatr 1984; 35 : 152-156.

[11] House JS, Landis KR, Umberson D. Social relationships and health. Science 1988; 241: 540-545.

[12] Haley WE, Clair JM, Saulsberry K. Family caregiver satisfaction with medical care of their demented relatives. Gerontologist 1992; 32: 219-226.

[13] Commissaris CJAM. Voorlichting over geheugenproblemen en dementie (Education about memory problems and dementia). Dissertation. Maastricht, 1993.

[14] Commissaris CJAM, Verhey FRJ, Ponds RWHM, Jolles J, Kok GJ. Public education about normal forgetfulness and dementia. Importance and effects. Patient Educ Couns 1994; 24: 109-115.

[15] Commissaris CJAM, Ponds RWHM, Verhey FRJ, Damoiseaux V, Kok G, Jolles J. Public information about normal forgetfulness and dementia: effectiveness of a systematically developed information brochure. Educ Gerontol 1995. In press.

[16] Cohen D, Eisdorfer C. Depression in family members caring for a relative with Alzheimer's disease. JAGS 1988; 36: 885-889.

[17] Colerick EJ, George LK. Predictors of institutionalization among caregivers of patients with Alzheimer's diease. JAGS 1986; 34: 493-498.
[18] Eagles JM, Craig F, Restall DB, Beattie JAG, Besson JAO. The psychological well-being of supporters of the demented elderly. Br J Psychiatr 1987; 150: 293-298.

[19] Zung WWK. A self-rating depression scale. Arch Gen Psychiatr 1965; 12: 63-70.

[20] American Psychiatric Association. Diagnostic and statistical manual of mental disorders, 3rd editionrevised (DSM-III-R). Washington: APA, 1987.

[21] McKahn G, Drachman D, Folstein M, Katzman R, Price D, Stadlan EM. Clinical diagnosis of Alzheimer's disease. Report of of NINCDS-ARDRA workgroup on Alzheimer's disease. Neurology 1984; 34: 939-944.

[22] Verhey FRJ, Jolles J, Ponds RWHM, Rozendaal N, Plugge L, Vet HCW de, Vreeling FW, Lugt PJM van der. Diagnosing dementia: a comparison between a monodisciplinary and multidisciplinary approach. J Neuropsychiatr Clin Neurosci 1993; 8: 78-85.

[23] O'Connor DW, Pollit PA, Brook CPB, Reiss BB, Roth $M$. Does early intervention reduce the number of elderly people with dementia admitted to institutions for long term care? Br Med 1991; 302: 871-875.

[24] Berg BK, Eckhoff-Biagi P, Hebert P, Rodell D, Sprafrin R. Patient education needs assessment: constructing a generic guide. Patient Educ Couns 1987; 9: 199.

[25] Mesters I, Meertens R, Mosterd N. Multidisciplinary cooperation in primary care for asthmatic children. Soc Sci Med 1991; 32: 65-70.

[26] Cromwell SL. The subjective experience of forgetfulness among elders. Qual Health Res 1994; 4: 444-462. 